\title{
Pharmacognostic, physiochemical and Phytochemical Profile of Alpinia galanga (L.) Willd. and Alpinia calcarata Roscoe
}

\author{
Silvy Mathew \\ Post Graduate Department of Botany, Vimala College (Autonomous), Thrissur, Kerala, India
}

Available online at: www.isroset.org

Received: 11/Nov/2018, Accepted: 05/Dec/2018, Online: 31/Dec/2018

\begin{abstract}
Alpinia galanga and Alpinia calcarata (Zingiberaceae), are rare, fast disappearing, threatened species and well known ayurvedic herbs and are used as medicine due to anti-bronchitis, anti-inflammatory, anti-cancerous, anti-cough, antidiabetic and anti-bacterial properties. The aim of present study was to gather information for the systematic identification and authentication of these valuable species as per WHO guidelines. Powdered leaves of A.calcarata showed high alcohol soluble extractive value, high moisture content, total ash value than rhizome powder and contrary in A.galanga. On the basis of fluorescence analysis rhizomes of these species carry more active ingredients chiefly used for therapeutical purposes. The presences of alkaloids, steroids, flavonoids etc. were confirmed during preliminary phytochemical screening. The pharmacognostic characters obtained in the present investigation might be useful in drug industry for the identification, authentication and quality of commercial samples supplied by suppliers and will be very useful in designing the monograph on these drugs in the Indian Pharmacopoeia.
\end{abstract}

Keywords: A. calcarata, A. galanga, phytochemical, Pharmaceutical, Physiochemical.

\section{INTRODUCTION}

The world is now focusing towards herbal medicine or phytomedicine to repair and strengthen bodily systems (especially the immune system that could properly fight foreign invaders) and help to destroy pathogens without toxic side effects. Since time immemorial man has used various parts of plants in the treatment and prevention of many ailments[1,2,3]. Plants constitute one of the major sources of drugs in modern as well as traditional medicine throughout the world [4,5]. According to WHO, the macroscopic and microscopic description of medicinal plants is the first step towards establishing the identity and degree of the purity of such materials and should be carried out before any tests are undertaken [6]. Several plants checked for antimicrobial and other activities, for example The Eupatorium odoratum leaf material shows higher microbial properties and have various compounds with pharmacological importance[7] and Methanol extract of Morchella esculenta showed highest free radical scavenging effect at concentration of $100 \mu \mathrm{g} / \mathrm{ml}$ and the IC50 value of extract was $49.8821 \mu \mathrm{g} / \mathrm{ml}[8]$.

Accurate identification is crucial before chemists and pharmacognosists can search for new chemical substances from plants and repeat their experiments [9]. An important factor, which contributes to the consistent quality of herbal products, is to have an adequate control of the quality of medicinal plants harvested or used [10]. Any loss in a particular chemical may result in loss of pharmacological action of that herb [11]. The histological and anatomical characters are necessary for the identification of plant species. More than $80 \%$ of the developing world continues to rely on traditional medicines predominantly plants, for its primary health care $[12,13]$. So, Pharmacognosy is one method for correctly determining the botanical identity of the sample even in dried or in powdered condition $[14,15]$.

Standardization of medicinal plants is global perspective [16]. Also, morphological and anatomical studies are significant for recognizing plants [17]. The present study reveals standardization profile for A. calcarata and A. galanga, family Zingiberaceae the data would be of immense value in botanical identification and authentication of plant drugs and would enable in preventing any adulteration. In zingiberaceae, anatomical studies are very few, some of the scientists only studied the general anatomy [18]. There are reports on the root apical organization in Zingiberaceae [19] and the occurrence and role of fugacious cambium in rhizome growth of turmeric [20]. There is also investigated the pharmacognosy of Curcuma species $[21,22,23]$. Thus the present study also intends to additionally add fluorescent microscopic studies on these selected species [24]. 
This article deals with the research on pharmacognostical studies of A.calcarata and A.galanga includes physiochemical analysis, fluorescence analysis, anatomical studies and phytochemical studies to determine the quality and purity of the plant materials. The medicinal plants selected for the present study and the importance of these plants is briefly mentioned in Introduction Section of this article followed by the objective of the study. The plant collection, Herbarium preparation and various methodology used in investigating rhizome, leaf of A.calcarata and A.galanga for physiochemical analysis and phytochemical studies have clearly mentioned in Methods and Methodology Section. The results observed in various investigation is neatly tabulated and for clear understanding of the results it is represented with photographs. The results are thoroughly discussed by comparing with previous works in Results and Discussion Section. Finally the article is concluded with recommendation in Conclusion Section.

\section{MATERIALS AND METHODS}

In the present work we used the methodologies like plant material collection, physiochemical analysis, anatomical studies and phytochemical studies. The samples were collected, air dried and powered. Also, preserved in Rapinat Herbarium and Centre for Molecular Systematics, St.Joseph's College (Autonomus), Tiruchirappalli (Voucher Numbers: RHT 65267 \& 65268 ) for future reference.

Fig. 1. a \&b) A.calcarata- habit \& inflorescence, c \&d) A.galanga - inflorescence \& single flower
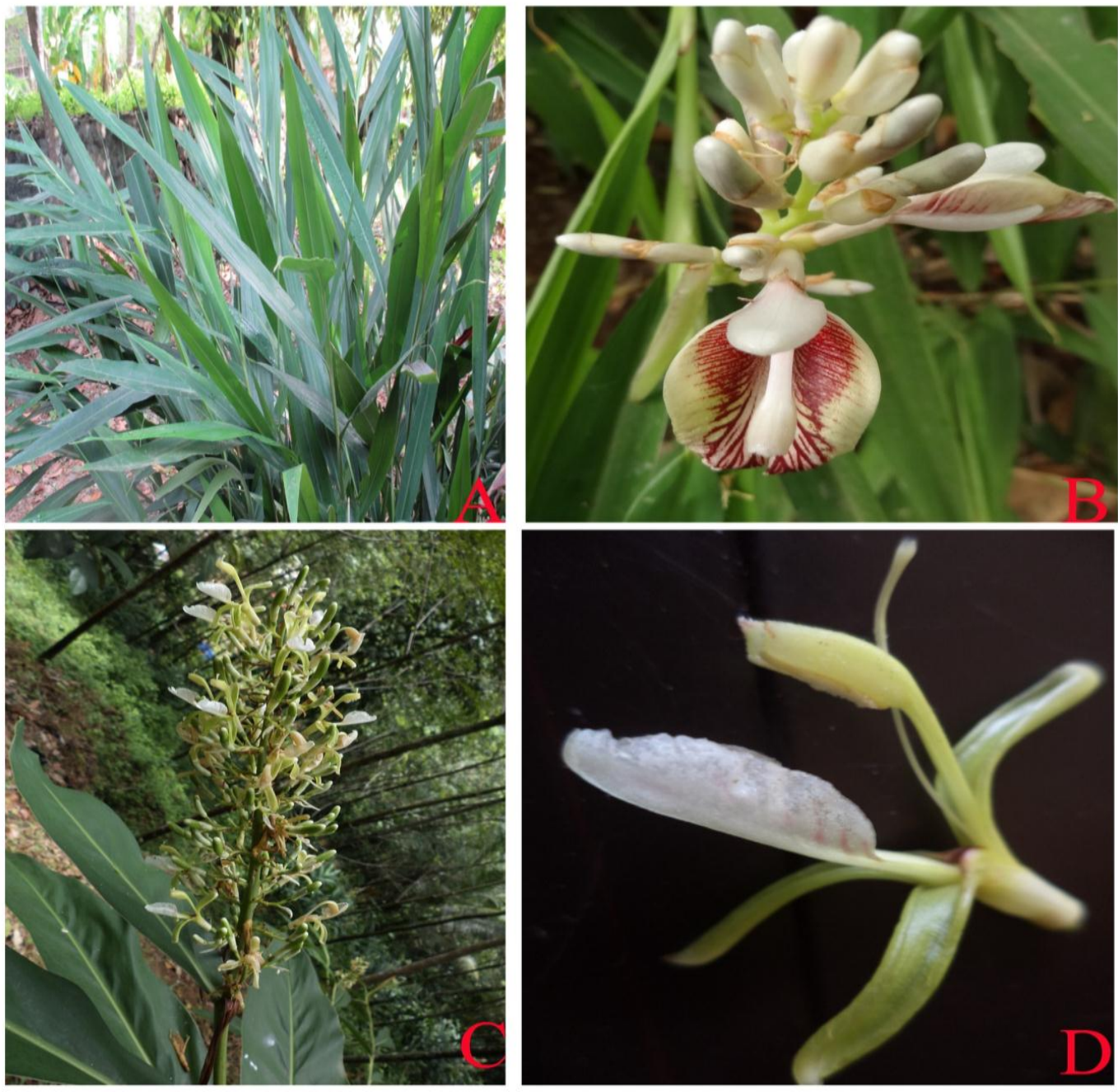

Physiochemical parameters were determined for rhizome and leaf powder of A.calcarata according to methods described in WHO guideline. Physiochemical analysis included fluorescence analysis, moisture content, total ash, water 
soluble ash, acid insoluble ash, alcohol soluble extractive and water soluble extractive to determine the quality and purity of the plant materials. Pharmacognostic standardization was also done as per WHO guidelines.

Many drugs show fluorescence when their powder is exposed to ultraviolet rays. The leaf and rhizome powder of A.calcarata and A. galanga were subjected to powder studies by adding the chemical reagents. A small quantity of dried powder was placed on a grease free clean microscopic slide and 1-2 drops of freshly prepared reagent solution were added, mixed by gentle tilting the slide. The colour change was noted in three times powder as such and then added reagents were performed under day light, $254 \mathrm{~nm}$ and $354 \mathrm{~nm}$ UV light.

For anatomical studies fresh specimens used and the transverse sections of the rhizomes, fresh leaves through the midrib were also cleared with $\mathrm{NaOH}$ and mounted in glycerine medium after staining and observed under fluorescent microscope. Microscopic descriptions of tissues were supplemented with microphotographs which were taken using a Nikon E - 400 (Japan) fluorescent microscope. The rhizome extracts for phytochemical screening were done with different solvents by using serial extraction using a soxhlet apparatus.

\section{RESULTS AND DISCUSSION}

Adulteration and misidentification of medicinal plants can cause serious health problems to consumers and legal problems for the pharmaceutical industries. Some constituents showed fluorescence in the visible range in daylight. The addition of various chemical agents to rhizome powder changed its colour to blackish green, brownish red, brownish yellow, dark brown, dark brownish green, dark greenish brown, dark yellow, light brown, pale brown, reddish green, pale yellow, reddish brown and yellowish brown (Table.1).

But in the case of leaf powder, there is slight colour changes like black, brownish dark green, blackish green, dark brown, dark brownish green, dark green, dark greenish brown, dark reddish green, dark reddish yellow, dark yellowish brown, greenish brown, greenish yellow, light brown, light green, light greenish brown, light yellow, light yellowish brown, pale green, reddish green, yellowish brown and yellowish dark brown. Hence crude drugs are often assessed qualitatively in this way and it is an important parameter for pharmacognostic evaluation of crude drugs.

Table. 1. Fluorescent analysis

\begin{tabular}{|l|l|l|l|l|l|l|}
\hline \multirow{2}{*}{ Reagents } & \multicolumn{2}{l}{ A.C- RP } & \multicolumn{2}{l|}{ A.G- RP } \\
\cline { 2 - 7 } & Day Light & $\mathbf{( 2 5 4} \mathbf{~ n m})$ & $\mathbf{( 3 6 5 n m})$ & Day light & $\mathbf{( 2 5 4} \mathbf{~ n m})$ & $\mathbf{( 3 6 5} \mathbf{~ n m})$ \\
\hline Powder + Con. $\mathrm{HCl}$ & PB & BG & BG & DB & BG & BG \\
\hline Powder +Con. $\mathrm{H}_{2} \mathrm{SO}_{4}$ & DB & RG & RG & LB & DB & RG \\
\hline Powder+ $50 \% \mathrm{H}_{2} \mathrm{SO}_{4}$ & YB & DB & BG & DB & DB & RG \\
\hline Powder + Con. $\mathrm{HNO}_{3}$ & YB & DB & DBG & DB & DB & RB \\
\hline Powder+GAA & LB & LB & DB & LB & DB & DB \\
\hline Powder + Picric acid & PY & BY & DY & BY & DY & DY \\
\hline Powder + $1 \mathrm{NaOH}$ & DB & DB & DB & PB & DB & DB \\
\hline Powder + 1N NaOH & LB & LB & DB & LB & YB & YB \\
\hline Powder + Chloroform & YB & DB & DB & PB & YB & DB \\
\hline
\end{tabular}

Extractive values are representative of the presence of the polar or nonpolar extractable compounds in a plant material [25]. It also gives an idea about the chemical constituents present in the drug and useful in the determination of exhausted or adulterated drugs. Table 2 shows that powdered rhizome have high alcohol soluble extractive value (22.84\%). Water soluble extractive value can be used to indicate poor quality, adulteration with an unwanted material, or incorrect processing of the plant drug during the processing of drying, storage and so on (18.53\%) and in A.galanga is $12.55 \%$. Acid insoluble ash of leaf powder of A. calcarata is comparatively less in amount (0.91\%), but in rhizome powder it is $2.38 \%$ and vice versa in A.galanga. 
Moisture is an inevitable component of plant drugs, insufficient drying leads to spoilage by moulds and bacteria and makes possible the enzymatic destruction of active principles. Moisture content is higher in leaf powder $(3.33 \%, 4.11 \%)$ than rhizome powder $(1.85 \%, 3.87 \%)$ in A.calcarata and A.galanga respectively. Also, total ash value is $7.83 \%, 4.05 \%$ in leaf powder and $6.56 \%, 1.63 \%$ in rhizome powder of A.calcarata and A.galanga respectively. Compared to rhizome powder water soluble ash is higher in leaf powder $2.79 \%$ and 2.05 .

Table.2. Physiochemical analysis in A.calarata and A. galanga

\begin{tabular}{|l|l|l|l|l|l|}
\hline \multirow{2}{*}{ SI.No. } & \multirow{2}{*}{ Parameters } & \multicolumn{2}{|r|}{ A.calcarat } & \multicolumn{2}{r|}{ A.galanga } \\
\cline { 3 - 6 } & & Leaf & Rhizome & Rhizome & Leaf \\
\hline 1 & Moisture & $3.33 \%$ & $1.85 \%$ & $4.11 \%$ & $3.87 \%$ \\
\hline 2 & Total Ash & $7.83 \%$ & $6.56 \%$ & $4.05 \%$ & $1.63 \%$ \\
\hline 3 & Acid Insoluble ash & $0.91 \%$ & $2.38 \%$ & $1.09 \%$ & $0.72 \%$ \\
\hline 4 & Water Soluble Ash & $2.79 \%$ & $1.73 \%$ & $2.05 \%$ & $1.98 \%$ \\
\hline 5 & Alcohol Soluble extractive & $14.5 \%$ & $22.84 \%$ & $7.91 \%$ & $8.55 \%$ \\
\hline 6 & Water soluble extractive & $12.79 \%$ & $18.53 \%$ & $11.53 \%$ & $12.55 \%$ \\
\hline
\end{tabular}

In A. galanga the rhizome is highly branched with yellowish colour, cylindrical, $2-8 \times 2-3 \mathrm{~cm}$, single layered epidermis and pericycle, cortex with numerous vascular bundles and aggregation of starch grains (fig.2.). In A. calcarata rhizome is less branched with creamy yellow, cylindrical, $2-6 \times 2 \mathrm{~cm}$, single layered epidermis and pericycle, outer cortex with vascular bundles less than inner cortex and mostly with oval shaped starch grains. Pith is made up of wide parenchymatous cells and they are circular to angular, compact and with no intercellular spaces.

Fig.2. Anatomy of A.galanga - rhizome - (A,B), leaf (C), Anatomy of A.calcarata- F,H- rhizome, D,E,G- leaf

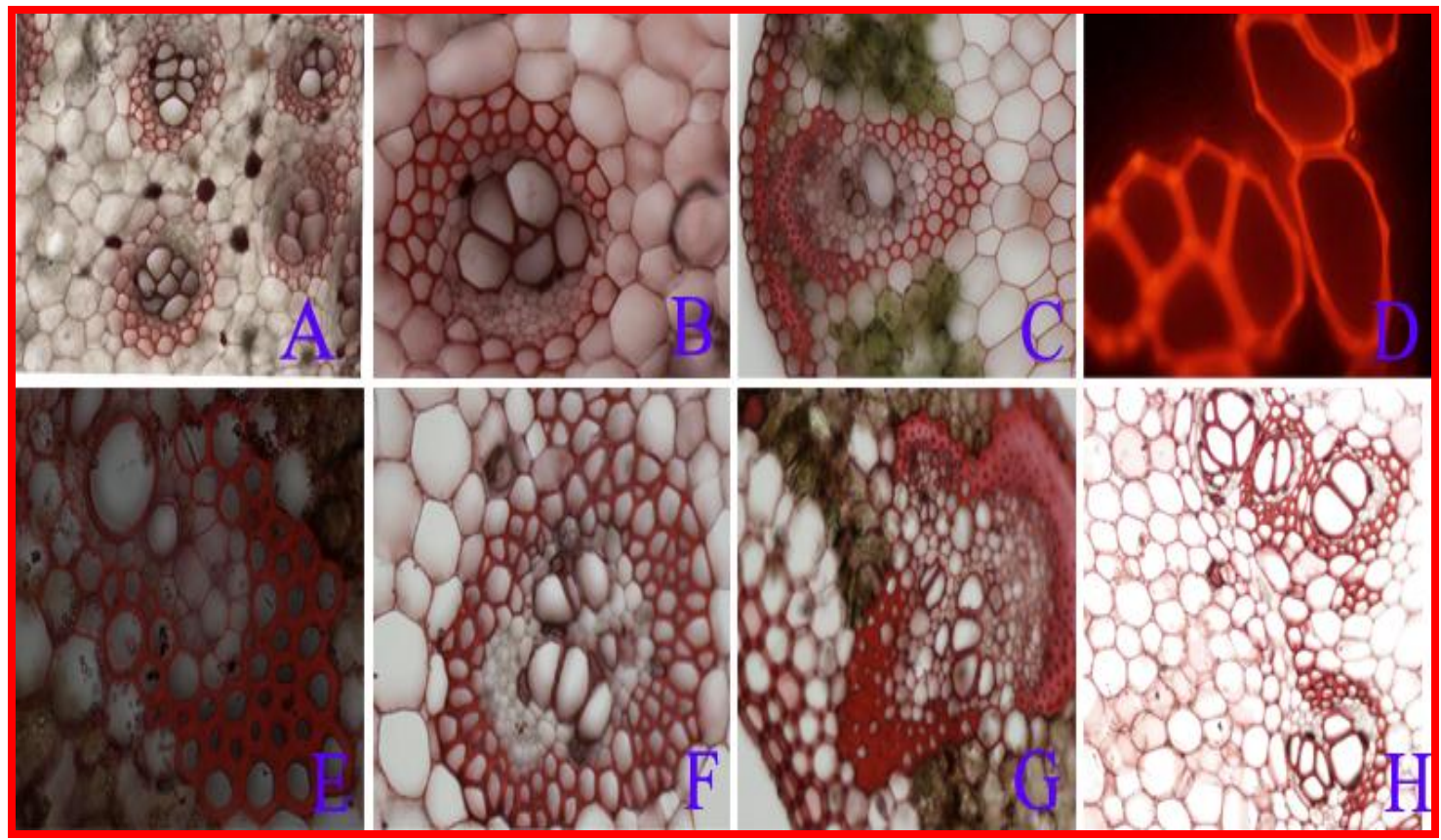

The leaf anatomy in both species showed numerous vascular bundles. The upper and lower epidermis consist of one row of elongated cells and a single layered epidermis in abaxial and in adaxial sides and with wide, tangentially oblong, thick walled cells with a thin cuticle, cortex with large parenchyma cells, vascular bundle with xylem and phloem cells and the 
presence of a bundle sheath and its extension upto the lower epidermis. The central cells of the mesophyll are large parenchyma cells alternating with the vascular bundles. The xylem consists of one raw of vessels with large metaxylem towards the upper epidermis. The mesophyll tissue is not differentiated into palisade and spongy parenchyma cells; it consists of 4 or 5 layers of chlorenchymatous cells.

The preliminary phytochemical investigation of methanolic rhizome extract of A. calcarata and A.galanga revealed the presence of sterols, alkaloids, flavanoids, phenols, carbohydrates etc. The curative properties of medicinal plants are perhaps due to the presence of various secondary metabolites such as alkaloids, flavanoids, glycosides, phenols, saponins, sterols etc. The phytochemical screening on qualitative analysis shows that the rhizomes of both species are are rich in sterols, anthraquinones etc. which are popular phytochemical constituents. Therefore, the data generated from these experiments have provided the chemical basis for the wide use of this plant as a therapeutic agent for treating various ailments.

Table. 3 . Phytochemical screening of methanolic extracts of A.calcarata and A.galanga

\begin{tabular}{|c|c|c|c|c|}
\hline \multirow{2}{*}{ Constituents } & \multicolumn{2}{|c|}{ A.calcarata } & \multicolumn{2}{|l|}{ A.galanga } \\
\hline & Leaf & Rhizome & Leaf & Rhizome \\
\hline Carbohydrates & ++ & -- & $-\quad-\quad+$ & ++ \\
\hline Phenols & --+ & -+ & --+ & --+ \\
\hline Flavonoids & ++ & ++ & ++ & +++ \\
\hline Sterols & ++ & +++ & ++ & +++ \\
\hline Alkaloids & -+ & ++ & -- & -- \\
\hline Anthraquinones & -+ & ++ & -+ & -+ \\
\hline Amino acid test & -+ & ++ & -+ & -+ \\
\hline Fixed oils and fats & -- & -- & -+ & -+ \\
\hline
\end{tabular}

\section{CONCLUSION}

The present study was undertaken to establish the scientific evidence for the detection of adulteration related to medicinal plant drug preparations. From the above study it may concluded that A. calcarata and A.galanga are useful in healthcare, so we have to conserve the plants for future generation. Phytochemical studies revealed that these species contain many active compounds will be obliging in ayurvedic medicine. Pharmacognostical studies were suited to standardize the plant and to check the adulteration in drug powder. The results obtained would serve as a reference for identification of rhizomes and leaves of $A$. calcarata and A. galanga commercially available and to differentiate them from their substitutes and adulterants.

\section{REFERENCES}

[1]. Chah KF, Eze CA, Emuelosi CE, Esimone CO, “Antibacterial and wound healing properties of methanolic extracts of some Nigerian medicinal plants", Journal of Ethnopharmacology, Vol.104, pp. 164 - 167, 2006.

[2]. Brindra P, Saraswathy A, "Pharmacognostic identification of Ayurveda drug sources used in skin diseases", Proceedings of International congress on ayurveda. Chennai. Tamilnadu. India,Vol.5, pp.28 - 30, 2000.

[3]. Cutler DF, Botha CEJ, Stevenson DW, "Plant anatomy: An applied approach", United kingdom: Blackwell publishing, 2008.

[4]. Suri RK, Chaudhari DC, Jaffer R, “Commercially important medicinal plants from forest”, J. Eco. Bot. Phytoche. Vol.3, No.2, pp. 129 140, 1992.

[5]. Fabricant DS, Farnsworth NR, "The value of plants used in traditional medicine for drug discovery", Environ. Health. Pers. Vol.109, No.1, pp. $69-75,2001$.

[6]. WHO, "Quality control methods for medicinal plant materials", Geneva, Switzerland, 1998.

[7]. Ramesh P and Subramani A, Effect of antimicrobial activity of Eupatorium odoratum against clinical microbes, International Journal of Scientific Research in Biological Sciences, Vol.5, Issue.5, pp.30-35, 2018.

[8]. D. R. Baba, P. M. Junaid, F. Khan, R. Singh, Nitric Oxide Scavenging Activity of Bioactive Compounds Present in Methanolic Extract of Morchella esculenta, International Journal of Scientific Research in Biological Sciences, Vol.5, Issue.5, pp.39-41, 2018.

[9]. Khatijah Hussain, Anatomical atlas of Malaysia medicinal plants, Malaysia : Penerbit Universiy Kebangsaan Malaysia, Vol.1, 2006.

[10]. Nasreen S, Radha R, Jayashree N, Selvaraj B, Rajendran A, "Assessment Quality of Tinospora cordifolia (Willd.) Miers. (Menispermaceae): Pharmacogonostical and Phyto-Physiochemical profile"Pharmacie Globale, Vol.5,No.03,pp.1- 4,2010.

[11]. Sumathy H, Sangeetha J, Vijayalakshmi K, "Chromatographic fingerprint analysis of Ixora coccinea methanolic flower extract", Int. J. Pharm. Sci. Drug Res, Vol.3, No.4,pp. 327 - 330,2011. 
[12]. Ulhe SK, Narkhede SD, "Histological and phytochemical studies on aromatic plant, Anisomeles indica (L.) of family Lamiaceae (M.S.) India”. ,Int. J. Life Sci, Vol. 1, No.4, pp. 270 - 272,2013.

[13]. Niranjan Sutar, Ranju Garai, Uma Shankar Sharma, Priyanka Goyal, Gangotri Yadav, "Pharmacognostic studies of the Achyranthes aspera Leaves", Int. J. Com. Pharm, Vol. 2, No.5, pp. 1-3, 2011.

[14]. Surendrakumar M (2011). Evaluation of antimicrobial activities of Aristlochia indica (Linn.). Int. J. Pharm. Pharm. Sci. $3(4)$ : 271 - 272.

[15]. Balandrin MF, Kinghorn AD, Fransworth NR, "Plant-derived natural products in drug discovery and development. An over view", In Kinghorn AD, Baladrin MF (Eds). Human Medicinal agents from plants, ACS symposium series 534. Ame. Che. Soc. Washington. USA. 1993.

[16]. Niranjan Sutar, Ranju Garai, Uma Shankar Sharma, Priyanka Goyal, Gangotri Yadav, "Pharmacognostic studies of the Achyranthes aspera Leaves", Int. J. Com. Pharm, Vol.2, No.5, pp.1 - 3, 2013.

[17]. Poornima N, Umarajan KM, Babu K, Studies on anatomical and phytochemical analysis of Oxystelma esculentum (L.F.) R. br. Ex Schltes. Bot. Res. Int, Vol. 2, No.4, pp. 239 - 243, 2009.

[18]. Tomlinson PB, Anatomy of the monocotyledons. III. Commelinales- zingiberales. In: Metcalfe CR (Ed.) Claredon Press. Oxford. 341 $360,1969$.

[19]. Pillai SK, Pillai A, Sachdeva S, Root apical organization in monocotyledons- zingiberaceae. Proc. Ind. Acad. Sci. (B). Vol. 53, pp. 240 256,1961 .

[20]. Adel Nadjib Chaker, Habiba Boukhebti, Farida Sahli, Rima Haichour, Rachid Sahraoui , "Morphological and anatomical study of two medicinal plants from Genus Mentha”, Adv. Env. Biol,Vol. 5, No.2,pp. 219 - 222, 2011.

[21]. Mazumder R, Bhattaharya S, Jha S, Mazumder A, Jyoti Kumari, Sanjay Jha, "Studies on pharmacognostical features of Curcuma domestica Val", Anci. Sci. Life, Vol. 26, No.4, pp. 37- 41,2007.

[22]. Chitra M, Thoppil JE, "Pharmacognostical and phytochemical studies on Curcuma amada (L.) rhizome (Zingiberaceae)", Anc. Sci. Life. Vol. 22, No. 2,pp. $25-33,2002$.

[23]. Yasodamma N, Chaithra D, Alekhya C, "Pharmacognostic evaluation of Curcuma neilghierrensis WT", Int. J. Pharm. Pharm. Sci. Vol.6, No.2, pp. $159-168,2014$.

[24]. Krishnamurthy KV, "Methods in cell wall cytochemistry", CRC Press. LLC. New York. 30.2000.

[25]. Arambewela LSR, Arawwawala LDAM, "Standardization of Alpinia calcarata Roscoe rhizomes", Pharma Res, Vol. 2,No.5,pp. 285 288,2010 .

\section{Author Profile}

Dr. Silvy Mathew, Assistant professor, Post Graduate Dept. of Botany, Vimala College (Autonomous), Thrissur. Awarded PhD in Botany-Molecular Systematics from Bharathidasan University, Tiruchirappalli and Published 17 research papers on Molecular studies, Phytochemical analysis, invitro studies and nanoparticles. She has around 7 years of teaching experience in different subjects related to botany. She presented research findings in 3 international and 5 national seminars. She is serving as the editorial board member of 3 international and 3 national journals and also resource person in national seminars, college programmes, other social functions and conducted workshops in national seminars. She published 32 DNA sequences and submitted in the public database, ie, Genbank and published one book chapter and engaged in writing books. She received most popular article award in international level. Completed one research project funded by KSCSTE as principal investigator and have one ongoing research project funded by KSCSTE as principal investigator. She has membership in professional bodies.

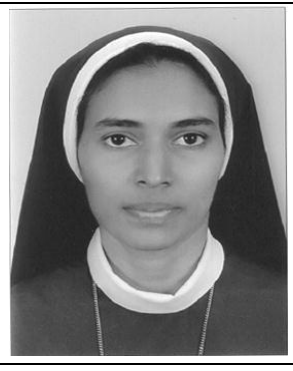

